\title{
POPULAÇÃO EM SITUAÇÃO DE RUA FACE À PANDEMIA: SISTEMATIZAÇÃO DA ASSISTÊNCIA DE ENFERMAGEM ${ }^{1}$
}

\section{Bruno Cassol Camera², Isadora Cardoso Pereira ${ }^{2}$, Elisa Sampaio Von Muhlen ${ }^{3}$, Ligia Maria Terra Fontella ${ }^{3}$, Dirce Stein Backes ${ }^{4}$}

\section{RESUMO}

A pandemia em curso, causada pelo vírus Sars-CoV-2, induziu medidas preventivas, tais como como o isolamento e distanciamento social, a utilização de álcool em gel, máscaras e outros. Quais as medidas para a População em Situação de Rua, considerando que a mesma vive em extrema pobreza, isto é, sem moradia fixa e exposta a riscos de toda ordem? Essa população enfrenta dificuldades em acessar aos serviços de saúde seja por questões de locomoção ou preconceito. Nesse processo, os Consultórios de Rua mostram-se importantes na busca da melhoria da qualidade de vida deste público alvo. Nesse percurso, a Sistematização da Assistência de Enfermagem se constitue em metodologia científica capaz de avaliar, otimizar e qualificar o processo de cuidado da enfermagem, à luz de referenciais que visam ampliar percepções teórico-práticas. No sentido de visibilizar a prática social do enfermeiro, o presente estudo teve por objetivo desenvolver a Sistematização da Assistência de Enfermagem em População em Situação de Rua, à luz do pensamento da complexidade.

Palavras-chave: Pandemia; Pessoas em Situação de Rua; Cuidado em enfermagem;

\begin{abstract}
We are living in times of pandemic caused by the Sars-CoV-2 virus and, as prevention measures, measures of social isolation, social distancing, use of alcohol gel and masks were enacted. The Homeless Population (THP) are even more vulnerable in this context, as they live in extreme poverty and do not have a permanent home, being exposed to various risks. This population faces difficulties in accessing health services, whether for reasons of mobility or prejudice, and Street Clinics are important in the pursuit of improving the quality of life of the THP. The Systematization of Nursing Care is an instrument used to assess, optimize and qualify nursing care and this process needs a broad and contextualized look that helps to understand the integrality of each individual. With an expanded and humanized view, Edgar Morin's Complexity Theory helps us to reflect on this uncertain moment of global crisis.
\end{abstract}

Keywords: Pandemic; Homeless people; Nursing care.

Eixo Temático: Direitos, Políticas Públicas e Diversidade (DPD)

\footnotetext{
${ }^{1}$ Estudo de caso teórico-prático

${ }^{2}$ Acadêmico do Curso de Enfermagem - Universidade Franciscana. E-mail: camera.cbruno@gmail.com; isacppereira@gmail.com.

${ }^{3}$ Mestranda do Curso de Enfermagem - Universidade Franciscana. E-mail: elisasvm@yahoo.com.br; ligia.fontella@ufn.edu.br.

4 Doutora de Enfermagem. Responsável pela disciplina. E-mail: backesdirce@unifra.br.
} 


\section{INTRODUÇÃO}

Face à pandemia, a População em Situação de Rua (PSR), ou seja, pessoas que vivem em condição de extrema pobreza, que não possuem vínculos estáveis com suas famílias e utilizam-se de locais públicos para moradia temporária ou fixa (SILVA, et al,2017; BRITO et al., 2020), encontram-se ainda mais vulneráveis. A PSR, um grupo exposto a vários riscos, especialmente as drogas lícitas e ilícitas, condições precárias de higiene e infecções sexualmente transmissíveis, enfrentam dificuldades de acesso à saúde, seja por questões de locomoção ou preconceito. Nesse contexto, os Consultórios de Rua (CdeR) mostram-se uma alternativa importante a ser considerada.

As diretrizes de organização e funcionamento das equipes e do consultório, presentes na Política Nacional de Atenção Básica em Saúde (PNAB), foram ampliadas por meio da Portaria nำ122, de 25 de janeiro de 2011, que criou os CdeR. De forma móvel e territorializada, estes Consultórios possibilitam a implementação de estratégias que visam o cuidado em saúde da População em Situação de Rua. Possibilitam, também, a acessibilidade aos serviços de saúde oferecidos pelo Sistema Único de Saúde (SUS), além de facilitarem a circulação dos sujeitos na cidade e o acesso à espaços públicos de cultura e lazer. Desenvolve-se, a partir dessa iniciativa, um cuidado integral, contemplando o indivíduo em sua totalidade, isto é, como ser que possui sentimentos e que estabelece modos de estar e existir no mundo (CAMPOS, 2021).

Vive-se um momento pandêmico causado pelo vírus Sars-CoV-2, agravado pelas iniquidades sociais. A pandemia em curso induziu medidas preventivas, tais como como o isolamento e distanciamento social, a utilização de álcool em gel, máscaras e outros. As políticas, em geral, restringiram as aglomerações e exposições desnecessárias (SOARES et al., 2021). Quais as medidas para a População em Situação de Rua, considerando que a mesma vive em extrema pobreza, isto é, sem moradia fixa e exposta a riscos de toda ordem?

A Sistematização de Assistência de Enfermagem (SAE), sob esse impulso inovador de centrar-se nos moradores de rua, constitui, segundo Backes et al. (2016), 
uma metodologia científica capaz de avaliar, otimizar e qualificar o processo de cuidado em enfermagem. Este procedimento é exclusivo do profissional enfermeiro, contudo, é fundamental que a equipe de enfermagem seja incluída nesse processo. É necessário que o cuidado seja tecido conjuntamente, para assim ampliar e inovar o processo de trabalho, de forma a observar a totalidade do ser, de maneira integral e humanizada. A SAE se organiza em etapas metodológicas, quais sejam: histórico de enfermagem; diagnóstico de enfermagem; planejamento de enfermagem; implementação das ações traçadas; e avaliação dos cuidados realizados (PATRíCIO et al., 2019).

Esse processo circular e sistêmico envolve um olhar amplo e contextualizado. Nesse sentido, o pensamento da complexidade de Edgar Morin auxilia na compreensão da integralidade de cada indivíduo e instiga a inovar e repensar as estruturas, frente a uma situação tão complexa como a exposta no presente artigo. Dessa forma, sob a luz de uma abordagem mais humana, a teoria da complexidade possibilita reflexões e amplia possibilidades neste momento incerto de crise global (BACKES et at. 2020).

No sentido de visibilizar a prática social do enfermeiro, o presente estudo teve por objetivo desenvolver a Sistematização da Assistência de Enfermagem com População em Situação de Rua, à luz do pensamento da complexidade.

\section{METODOLOGIA}

Trata-se de um estudo de caso teórico-prático que intentou desenvolver a Sistematização da Assistência de Enfermagem em População em Situação de Rua, à luz do pensamento da complexidade. Utilizou-se, para tanto, notícias públicas previamente noticiadas, desenvolvidas por discentes do curso de Enfermagem de uma instituição de ensino superior da região central do Rio Grande do Sul. O estudo foi desenvolvido no decorrer do primeiro semestre letivo de 2021, como produto de aprendizagem para a disciplina de Fundamentos Teóricos Filosóficos em Enfermagem, sob orientação da professora responsável pela disciplina.

O estudo de caso é um método de pesquisa que utiliza, geralmente, dados qualitativos coletados a partir de eventos reais, com o objetivo de explicar, explorar ou 
descrever fenômenos atuais inseridos em seu próprio contexto. Caracteriza-se por ser um estudo detalhado e exaustivo de poucos, ou mesmo de um único objeto, fornecendo conhecimentos profundos (FLYBJERG, 2006; THOMAS, 2010).

\section{RESULTADOS E DISCUSSÕES}

Descreve-se, na sequência, o detalhamento de cada uma das etapas da SAE, a partir de um caso fictício, quais sejam: Histórico de enfermagem; diagnóstico de enfermagem; planejamento de enfermagem; implementação das ações traçadas e avaliação dos cuidados realizados. No Histórico de Enfermagem (ou Coletas de Dados), efetua-se a anamnese e exame físico. Os Diagnósticos de Enfermagem constituem-se no julgamento clínico da junção dos dados coletados relacionados às reações humanas e a experiência de vida, objetivando delinear o foco do atendimento de enfermagem. O Planejamento estabelece os resultados esperados, ações e intervenções de enfermagem a serem realizadas na fase de Implementação e, na Avaliação, verifica-se a ocorrência de transformações e se há necessidade de adaptações ou reorganização nas etapas do processo de enfermagem para restabelecer a saúde da pessoa em situação de rua (UBALDO; MATOS; SALUM, 2015).

\subsection{HISTÓRICO DE ENFERMAGEM}

Morador de rua (fictício), 22 anos, natural de Itaqui - RS, pais falecidos, possui dois irmãos de 30 e 32 anos com vínculo fragilizado. Foi criado pela avó materna até completar 19 anos e mudou-se para a região central, no ano de 2019, em busca de emprego. No acolhimento, o morador apresentava fraqueza, discurso confuso, ansioso, sem realizar os cuidados de higiene corporal. Referente a história de vida pregressa contou que faz uso de substâncias psicoativas (SPA) desde a adolescência. Começou a usar maconha com 12 anos, álcool e crack com 16, nunca realizou tratamento para dependência química e relata que fazia uso de crack e álcool semanalmente.

Devido ao contexto pandêmico, alto índice de desemprego, falta de oportunidades, o morador passou a viver em situação de rua, provendo sua 
subsistência através de doações e venda de materiais recicláveis. Visto a situação de vulnerabilidade e risco social a que os indivíduos em situação de rua estão expostos, o morador começou a fazer uso abusivo de álcool e crack diariamente.

Usuário relata que buscou o serviço de pronto atendimento por estar sentindo dores abdominais, sudorese excessiva, cefaleia, diarreia e fraqueza. Foi medicado com dipirona e liberado sem referência ou encaminhamentos. Na sequência buscou serviço de atenção primária à saúde apresentando os mesmos sintomas.

Verificado os sinais vitais, Pressão Arterial: 120/80 mmHg; Frequência Cardíaca: 88 bpm; Frequência Respiratória: 18 mpm; Saturação: 98\%; Temperatura: $36,2^{\circ} \mathrm{C}$. Ao exame físico apresentou quadro de desnutrição, desidratação, ausência de higiene corporal, tosse com secreção e coriza, tórax simétrico, abdômen plano. $\mathrm{Na}$ ausculta pulmonar murmúrio vesicular presente e ruídos hidroaéreos presentes. Extremidades aquecidas e com boa perfusão periférica.

A partir do histórico de enfermagem do morado em estudo, realizou-se avaliação abrangente, bem como a elucidação da vivência conduzindo a investigação das reais necessidades humanas básicas e sua condição de saúde. O objetivo da assistência de enfermagem é prestar o cuidado conforme os diagnósticos identificados, possibilitando definir as intervenções para que se obtenha os resultados de incumbência do enfermeiro, relacionando a assistência de enfermagem nas adversidades que circundam o processo saúde doença (TEIXEIRA, et al. 2015).

A partir do histórico realizado, demostra-se, a seguir, quadro que contém o diagnóstico, o planejamento e a implementação do cuidado de enfermagem, à luz do pensamento da complexidade.

Quadro 1: Diagnóstico, planejamento e implementação de enfermagem

\begin{tabular}{|c|c|c|}
\hline Diagnóstico & \multicolumn{1}{|c|}{ Planejamento } & \multicolumn{1}{c|}{ Implementação } \\
\hline Invisibilidade social & $\begin{array}{l}\text { Criação de material informativo e } \\
\text { instigador sobre a realidade que } \\
\text { os moradores de rua atravessam } \\
\text { no período pandêmico. }\end{array}$ & $\begin{array}{l}\text { Veiculação de material } \\
\text { informativo e instigador no } \\
\text { jornal O Diário de Santa Maria. }\end{array}$ \\
\hline $\begin{array}{c}\text { Irreconhecibilidade } \\
\text { humana }\end{array}$ & $\begin{array}{l}\text { Criação de material informativo e } \\
\text { instigador sobre a realidade que } \\
\text { os moradores de rua atravessam } \\
\text { no período pandêmico. }\end{array}$ & $\begin{array}{l}\text { Veiculação de material } \\
\text { informativo e instigador no } \\
\text { jornal O Diário de Santa Maria. }\end{array}$ \\
\hline
\end{tabular}




\begin{tabular}{l} 
EDUCAÇÃO, SAÚDE \\
ETIECNOLOGIA \\
\hline 26 A 28 DE OUTUBRo DE 2021
\end{tabular}

Fonte: Contrução dos autores.

Os diagnósticos de enfermagem, de forma inovadora, buscam trazer uma reflexão mais complexa para o tema abordado. Essa população, muitas vezes é tirada da condição de humanidade, vivendo em condições sub-humanas, tendo seus direitos de acesso à saúde, renda mínima e moradia negados. Sendo assim, excluídos da sociedade, e até mesmo da condição de indivíduos humanos.

Para ampliar a visibilidade social da população em situação de rua e fomentar uma reflexão crítica ampliada, elaborou-se uma matéria jornalística, a qual foi veiculada no Jornal O Diário, conforme segue:

Instigados por este questionamento, fomos às ruas de Santa Maria para ouvir a história de vida de algumas pessoas que vivem nesta situação.

"De acordo com a Secretaria Nacional de Assistência Social, a população em situação de rua se caracteriza por ser um grupo de pessoas oriundos de diferentes contextos, mas que têm em comum a condição de pobreza absoluta. Grande parte destas pessoas tem vínculos familiares interrompidos ou fragilizados, restando-lhes a "rua" como espaço de moradia e sustento. Sob esse enfoque, questiona-se: "no atual contexto pandêmico em que as dificuldades financeiras e sociais se aprofundaram, como sobrevivem as pessoas em situação de rua da nossa cidade?" Instigados por este questionamento, fomos às ruas de Santa Maria para ouvir a história de vida de algumas pessoas que vivem nesta situação. O primeiro relato é de um senhor de 67 anos, que vive na rua há cerca de três anos e se declara dependente alcoólico. $O$ mesmo relatou que, durante a pandemia, muitas pessoas têm fornecido comida, roupas e cobertores. Sensibilizado, relata que, durante as noites mais frias, jovens passam de carro distribuindo sopas quentes e marmitas. Atitudes de compaixão! Em continuidade, o mesmo relatou que, no ano passado, foi internado na UPA, onde além de tratamento medicamentoso, recebeu carinho, atenção e comida, pelo fato dos profissionais de saúde saberem do seu paradeiro nas ruas: "Senti-me bem atendido lá na UPA. Fui bem atendido mesmo". Outro relato é de um jovem de 29 anos. O mesmo disse que não lembra há quanto tempo mora nas ruas, mas que, por diversas vezes, buscou os serviços de saúde, e nem sempre foi respeitado, tendo a situação se agravado durante a pandemia. Em alguns momentos de sua fala, o morador evidenciou a falta de acolhimento às pessoas que vivem nessa condição de vulnerabilidade, principalmente em relação aos dependentes químicos e alcoólicos, conforme expresso: "A gente tá sendo excluído da sociedade... tem pessoas que tem má intenção. A gente tá, toda hora, sendo não só maltratado, mas excluído da sociedade". Forçados à exposição social, as pessoas em situação de rua buscam 
refúgio em ações desenvolvidas por organizações sociais e iniciativas individuais. Em eventos solidários, realizados na Rua Alberto Pascoalini e na Praça Saldanha Marinho, são distribuídos alimentos, cobertores e equipamentos de proteção individual. As pessoas em situação de rua são invisíveis aos olhos de uma parcela da sociedade. Em contrapartida, parte dos santa-marienses demonstram gestos diários de sensibilidade e solidariedade. Além dos itens básicos de sobrevivência, essas pessoas necessitam ser ouvidas e respeitadas. Afinal, somos todos humanos, cidadãos e merecedores de acolhimento, cuidado e amor. Atravessamos um período de extrema dificuldade, mas podemos reconhecer, nesses desafios, possibilidades para utilizar os óculos da compaixão e exercitar nossa fraternidade e solidariedade". ${ }^{5}$

\subsection{AVALIAÇÃO DE ENFERMAGEM}

Para colaborar com a visibilidade e instigar reflexões sobre a situação dos moradores de rua foi elaborada uma matéria jornalística, a qual foi veiculada em um Jornal de alcance regional (Jornal O Diário). Logo que foi publicada a nota, foi realizado um questionário com o auxílio da ferramenta "Google forms" e compartilhado com 10 voluntários (estudantes e professores de enfermagem), a fim de avaliar o processo teórico-prático. Na sequência, seguem recortes da avaliação dos participantes:

"De acordo com a Secretaria Nacional de Assistência Social, a população em situação de rua se caracteriza por ser um grupo de pessoas oriundos de diferentes contextos, mas que têm em comum a condição de pobreza absoluta. Grande parte destas pessoas têm vínculos familiares interrompidos ou fragilizados, restando-Ihes a "rua" como espaço de moradia e sustento. Sob esse enfoque, questiona-se: no atual contexto pandêmico em que as dificuldades financeiras e sociais se aprofundaram, como sobrevivem as pessoas em situação de rua da nossa cidade?". (A1)

"Forçados à exposição social, as pessoas em situação de rua buscam refúgio em ações desenvolvidas por organizações sociais e iniciativas individuais. Em eventos solidários, realizados na Rua Alberto Pascoalini e na Praça Saldanha Marinho, são distribuídos alimentos, cobertores e equipamentos de proteção individual". (A3)

"As pessoas em situação de rua são invisíveis aos olhos de uma parcela da sociedade. Em contrapartida, parte dos santa-marienses demonstram gestos diários de sensibilidade e solidariedade. Além dos itens básicos de sobrevivência, essas pessoas necessitam ser ouvidas e respeitadas. Afinal, somos todos humanos, cidadãos e merecedores de acolhimento, cuidado e amor". (A8)

\footnotetext{
${ }^{5}$ CAMERA, Bruno Cassol; PEREIRA, Isadora Cardoso; BACKERS, Dirce Stein. ISOLAMENTO SOCIAL: QUEM NÃO TEM CASA, SE ISOLA ONDE? Diário de Santa Maria, Santa Maria, 12 de julho de 2021. Disponível em: <https://diariosm.com.br/colunistas/colunistas-doimpresso/isolamento-social-quem-n\%C3\%A3o-tem-casa-se-isola-onde-1.2347110\#.YOyMIDnZWw0.whatsapp>. Acesso em: 08, set. 2021.
} 


\section{PUFN}

"Achei uma matéria muito interessante, importante e necessária. Como é falado no texto, os moradores de rua muitas vezes ficam invisíveis aos nossos olhos, levamos nossa vida como se situação de vida daquela pessoa fosse normal, e não é, é uma situação que requer nossa atenção, e para que isso aconteça muitas vezes precisamos que alguém nos diga, nos mostre a realidade, e foi o que vocês fizeram no texto! Parabéns!". (A9

Gráfico 1: Avaliação sobre as informações veiculadas

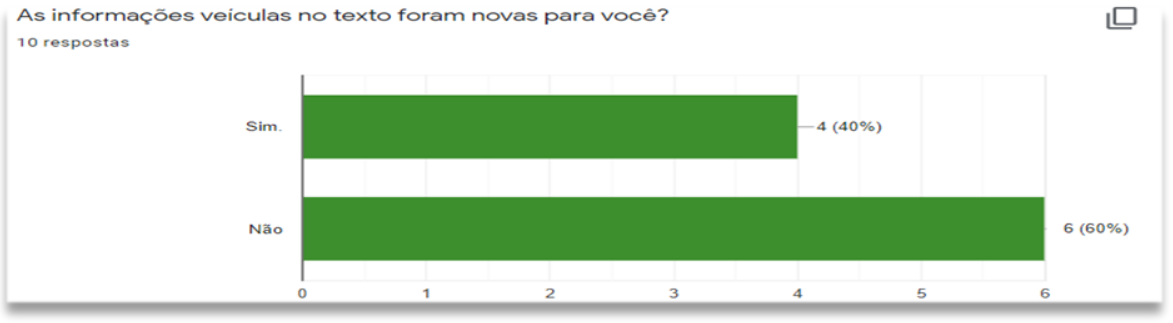

Gráfico 1: Contribuição para uma autoreflexão

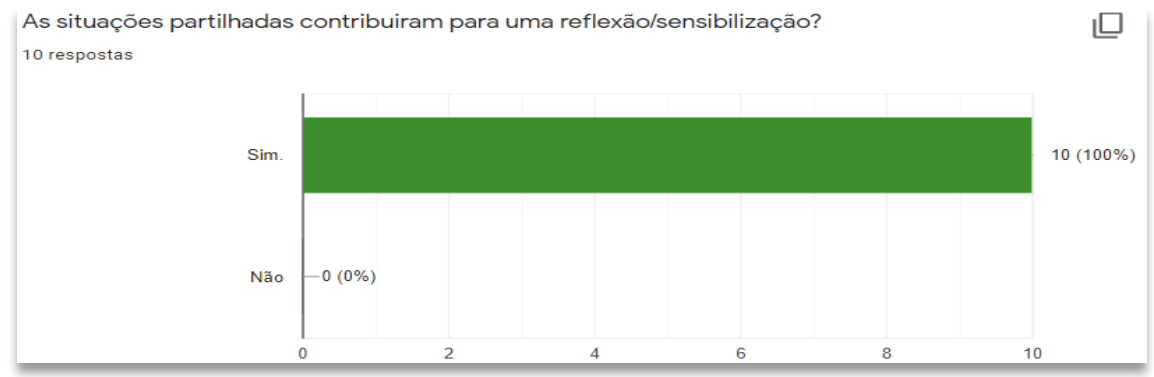

Gráfico 3: Relevância das informações

As informações publicadas foram relevantes?

10 respostas

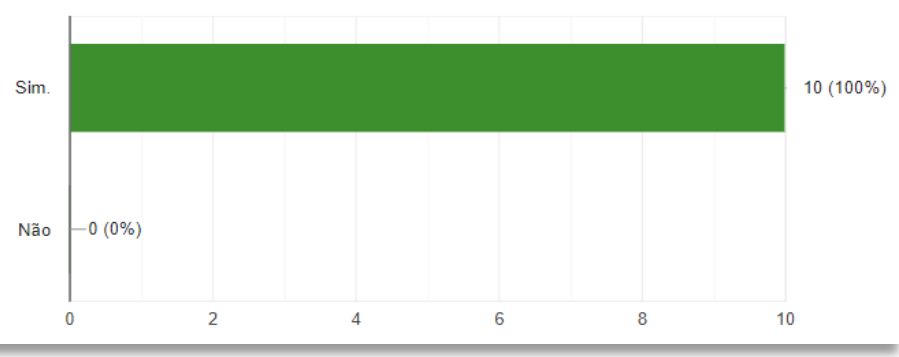

Representado nos dados acima, a análise da conjuntura que envolve a PSR no contexto pandêmico é necessária. Refletir sobre essa situação sob uma óptica humanizada, é inovar e instigar novas formas de pensar e agir. Existe uma grande fragmentação na nossa sociedade, na educação e também na humanidade, contribuindo assim para que tenhamos dificuldade de nos reconhecer enquanto irmãos e irmãs (seres que pertencem à mesma espécie). 
Segundo Morin (2007), a melhor forma de educar a nova geração, passa por uma educação integral, que possa levar em consideração o todo e também as partes. Nesse sentido, a situação complexa que envolve a PSR requer atitudes e reflexões humanizadas, que busquem escutar e incluir essas pessoas em sua condição de ser humano. A captação de depoimentos, seguida da elaboração e veiculação de uma nota em um jornal de grande circulação regional, mostra-se inovadora. Já que, traz elementos da realidade dessa população e instiga os leitores a repensar seus pensamentos.

\section{CONCLUSÃO}

Conclui-se, a partir da realização deste trabalho, que a pessoa em situação de rua está inserida em uma condição de extrema miséria e exclusão social com perda significativa da sua qualidade de vida e dos seus direitos fundamentais. Decorrente do fato de os moradores de rua estarem completamente expostos a riscos, tornandoos vulneráveis a qualquer tipo de violência e condições precárias de vida, é preciso que sejam estimuladas e fortalecidas as políticas inclusivas em âmbito da saúde pública.

Dessa forma, os profissionais da saúde são os principais a ajudarem na conscientização das pessoas que se encontram nessa situação. Com o objetivo de promover uma assistência integral e de qualidade, devem estar preparados para lidar com esses sujeitos de forma acolhedora e promovendo a educação em saúde. $\mathrm{O}$ papel do enfermeiro nesse contexto, tem como principal função promover a educação em saúde, e a partir dela levar sempre em consideração os contextos envolvidos como pessoal, físico, psicológico, espiritual, social, econômico e familiar, desenvolvendo a busca pessoal desses indivíduos pela conscientização do autoconhecimento, a autoconfiança e o autocuidado.

O trabalho evidenciou a desvalorização da pessoa em situação de rua, visto que são pessoas que são marginalizadas devido à alta falta de conhecimento das pessoas sobre esses sujeitos. Com a teoria da complexidade de Edgar Morin e futuros enfermeiros, devemos ver o indivíduo em sua totalidade, além da sua doença, devemos estar ao lado e promover a reinserção social dessa população. Com a 
finalidade de que os fatores de risco que tornam esse grupo vulnerável sejam reduzidos, em contraponto, incentivar o acesso aos serviços de saúde, já que é um espaço público com a função de cuidar, tratar e promover a saúde.

\section{REFERÊNCIAS}

BACKES, M.T. S, CARVALHO, K. M, SANTOS, E. K. A, BACKES, D. S. Novo coronavírus: o que a enfermagem tem a aprender e ensinar em tempos de pandemia?

Rev. Bras. Enfermagem, Disponível em: https://www.scielo.br/j/reben/a/8gnFNHnp36W6mWBJzHqWzYb/?lang=pt\&format=pd f. Acesso em 14 de agosto de 2021

BAIOTTO, A. I, RODRIGUES, E. M, PARIZOTTO, J. G. C, ZANARDO, G. M, ROSA, N. P, MELLO, S, KAEFER, C. T. Reflexões sobre a Sistematização da Assistência de Enfermagem. XVII Semin Interistitucional de Ensino, Pesquisa e Extensão, Unicruz. Disponível em: https://home.unicruz.edu.br/seminario/downloads/anais/cc/reflexoes\%20sobre\%20a \%20sistematizacao\%20da\%20assistencia\%20de\%20enfermagem.pdf. Acesso em 16 de agosto de 2021.

BRASIL. MINISTÉRIO DA SAÚDE. Resolução COFEN 358/2009. Disponível em: http://www.cofen.gov.br/resoluo-cofen-3582009 4384.html. Acesso em 16 de agosto de 2021.

CAMERA, Bruno Cassol; PEREIRA, Isadora Cardoso; BACKERS, Dirce Stein. ISOLAMENTO SOCIAL: QUEM NÃO TEM CASA, SE ISOLA ONDE? Diário de Santa Maria, Santa Maria, 12 de julho de 2021. Disponível em: https://diariosm.com.br/colunistas/colunistas-do-impresso/isolamento-social-quemn\%C3\%A3o-tem-casa-se-isola-onde-1.2347110\#.YOyMIDnZWw0.whatsapp. Acesso em: 08, set., 2021.

CAMPOS, A. C. F, RESENDE, A. S. A. Consultório de rua de Belo Horizonte e os desafios enfrentados na pandemia do COVID-19. Serviço Social em Perspectiva, v.5, n. 1, p.2527- 1849, jan/jun, 2021. Disponível em: https://www.periodicos.unimontes.br/index.php/sesoperspectiva/article/view/3423/35 21. Acesso em 20 de agosto de 2021 
GALVÃO, E. LOPES, G. S, DALCIN, C. B, PEREIRA, A. D, BACKES D. S. A sistematização da assistência de enfermagem com uma gestante colecionadora de materiais recicláveis. Disciplinaruim Scientia, v. 17, n. 1, p. 23-31, 2016. Disponível em: https://periodicos.ufn.edu.br/index.php/disciplinarumS/article/view/1905. Acesso em 12 de setembro de 2021.

HERMIDA, P. M. V, ARAÚJO, I. E. M. Sistematização da Assistência da Enfermagem: subsídios para implantação. Rev. Bras. Enfermagem, v. 59, n. 5, p. 675-9, set/out, 2006.

Disponível

em:

https://www.scielo.br/j/reben/a/ZSFn7Yhx8XNG5Wtvs3G66zF/?lang=pt\&format=pdf. Acesso em 13 de setembro de 2021.

MORIN, E. Introdução ao pensamento complexo. 3. Ed. Porto Alegre: Sulina, 2007. Disponível em: https://www.editorasulina.com.br/img/sumarios/313.pdf. Acesso em 13 de setembro de 2021.

SILVA, I. B. N, SILVA, D. F, LIMA, L. M, PATRíCIO, A. C. R. A, SILVA, R. A. R. Diagnósticos e interveções de enfermagem entre idosos em situação de rua. VI Congresso Internacional de Envelhecimento Humano. Disponível em: https://editorarealize.com.br/editora/anais/cieh/2019/TRABALHO EV125 MD1 SA1 ID487 23052019214703.pdf. Acesso em 16 de setembro de 2021.

SILVA, R.P. et al. Assistência de enfermagem a pessoas em situação de rua. Revista Reien. São Paulo, v. 7, n. 20, p.31-39, 2017. Disponível em: https://doi.org/10.24276/rrecien2358-3088.2017.7.20.31-39

SOUZA, C. L, DUARTE, A. C. S, VILELA, A. B. A, SANTOS, A. S, MAGALHÃES, D. L, SILVA, E. S. Ambiente na formação em saúde: Reflexões sobre hiperespecializção do ensino baseada em Edgard Morin. Braz. J. Of Devolop, v. 6, n. 7, p. 53513-53527, jul, 2020.

Disponível

em:

https://www.brazilianjournals.com/index.php/BRJD/article/view/14232/11851. Acesso em 10 de setembro de 2021.

TEIREIRA, G. A, CARVALHO, J. B. L, SILVA, A. L. M. A, SANTOS, S. B, ROSENTAL, T, LOPES, G. Sistematizaçãop do Processo de Enfermagem a pessoas em situação de rua. Revistas de Enfermagem UFPE on line. Recife, v. 9, n. 3, p:7169-74, mar., 2015. Disponível em: DOI: 10.5205/reuol.7505-65182-1-RV.0903201520 
EDUCAÇÃO, SAÚDE

ETECNOLOGIA

26 A 28 DE OUTUBRO DE 2021

\section{QUFN}

UBALDO, I, MATOS, E, SALUM, N. C. Diagnósticos de enfermagem da NANDA -I com base nos problemas segundo teoria de Wanda Horta , v. 20, n. 4, p. 687-694, 2015. Disponível em: https://revistas.ufpr.br/cogitare/article/view/40468/26628. Acesso em 19 de agosto de 2021. 